\section{Crustal thickness and Moho sharpness beneath the Midcontinent rift from receiver functions}

\author{
Moikwathai Moidaki, ${ }^{1}$ Stephen S. Gao, ${ }^{2}$ \\ Kelly H. Liu, ${ }^{2}$ Estella Atekwana ${ }^{3}$ \\ 'University of Botswana, Gaborone, \\ Botswana; ${ }^{2}$ Missouri University of Science \\ and Technology, Rolla, MO; ${ }^{3}$ Oklahoma \\ state University, Tulsa, OK, USA
}

\begin{abstract}
The Mesoproterozoic Midcontinent rift (MCR) in the central US is an approximately $2000 \mathrm{~km}$ long, $100 \mathrm{~km}$ wide structure from Kansas to Michigan. During the 20-40 million years of rifting, a thick (up to $20 \mathrm{~km}$ ) layer of basaltic lava was deposited in the rift valleys. Quantifying the effects of the rifting and associated volcanic eruptions on the structure and composition of the crust and mantle beneath the MCR is important for the understanding of the evolution of continental lithosphere. In this study we measure the crustal thickness $(\mathrm{H})$, and the sharpness of the Moho (R) at about 24 portable and permanent stations in Iowa, Kansas, and South Dakota by stacking Pto-S converted waves (PmS) and their multiples (PPmS and PSmS). Under the assumption that the crustal mean velocity in the study area is the same as the IASP91 earth model, we find a significantly thickened crust beneath the MCR of about $53 \mathrm{~km}$. The crustal $\mathrm{V}_{\mathrm{p}} \mathrm{N}_{\mathrm{s}}$ ratios increases from about 1.80 off rift to as large as 1.95 within the rift, which corresponds to an increase of Poisson's ratio from 0.28 to 0.32 , suggesting a more mafic crust beneath the MCR. The $\mathrm{R}$ measurements are spatially variable and are relatively small in the vicinity of the MCR, indicating the disturbance of the original sharp Moho by the rifting and magmatic intrusion and volcanic eruption.
\end{abstract}

\section{Introduction}

The crustal structure of Mesoproterozoic Midcontinent rift (MCR) is investigated by using receiver functions to determine the extent of crustal modification. The receiver function method was used in different parts of the world e.g. Baikal Rift by Gao et al. ${ }^{1}$ Arabian plate by Al-Damegh et al., ${ }^{2}$ and Afar rift by Dugda et al., ${ }^{3}$ in order to understand crustal evolution based on Poisson's ratio, $\mathrm{V}_{\mathrm{p}} / \mathrm{N}_{\mathrm{s}}$ ratio and crustal thickness. Receiver function stud- ies have not been done in the MCR but earlier geophysical investigations in MCR by Cannon et $a l .{ }^{4}$ have indicated a crustal thickening beneath the rift of about $45 \mathrm{~km}$, assumed to be caused by the presence of magmatic underplating above a modified lower crust, ${ }^{5}$ or a basaltic dome in the lower crust causing flexure of the upper crustal layers. ${ }^{6}$

Seismic studies by Hinze $e t$ al., ${ }^{7}$ Behrendt $e t$ $a{ }^{8}{ }^{8}$ indicated a more complex crust consisting of low velocity sedimentary rocks overlying a thick section of mafic volcanic rocks. The Consortium for Continental Reflection Profiling (CORCORP) deep seismic profiling in the 1970s across both limbs showed fault bounded basins of volcanic rocks overlain by thick clastic sedimentary rock units. ${ }^{8}$ Seismic reflection survey conducted in 1986 by Great Lakes International Multi-disciplinary Program on Crustal Evolution (GLIMPCE) in the Great Lakes provided images of the rift to subMoho depths based on seismic reflection profiles across the MCR in Lake Superior and Michigan. Moho reflections have been found to occur at 36-42, at Lake Huron and Lake Michigan. ${ }^{8}$ Complex Moho reflections were found within the Grenville orogeny at 12-13 s indicating a thicker crust assuming a velocity of $6.5 \mathrm{~km} / \mathrm{s}$ by Behrendt et al., ${ }^{8}$ Behrendt et al. ${ }^{9}$ On the MCR, a zone of reflections extending over $2 \mathrm{~s}$ was interpreted as evidence of magmatic underplating associated with $1100 \mathrm{Ma}$ based on the character of the seismic reflections and suggests a dipping Moho from about $12 \mathrm{~s}$ at the north end to about $14 \mathrm{~s}$ beneath the centre of the rift basin. The base of these reflections is interpreted to correspond to Moho with velocities of $\sim 8.1 \mathrm{~km} / \mathrm{s}$ reported at $55-56 \mathrm{~km}$ depth. ${ }^{10,11}$ Intense gravity anomalies are observed along the rift axes, positive anomalies are found where volcanic rocks are predominant and negative anomalies over sedimentary basins. ${ }^{11}$ The central gravity high within the MCR is interpreted as horst of mafic volcanic rocks. Interpretation of gravity data by Carmichael and Black ${ }^{12}$ showed that the average crustal thickness in the central Midcontinent is about $40 \mathrm{~km}$. The previous studies have contributed significantly to our understanding on crustal structure; however, this study will provide new insights on the crustal thickness $(\mathrm{H})$, and quantify the sharpness of Moho (R) by stacking teleseismic P-to$\mathrm{S}$ converted waves (PmS) and their multiples (PPmS and PSmS). Previous researchers suggested magmatic under-plating based on the observations of seismic reflection velocities but not quantitatively address quality of Moho beneath the rift. $4,5,7,8$

\section{Data}

Data used in this study was requested from IRIS Data Management Centre and consists of
Correspondence: Moikwathai Moidaki, University of Botswana, Physics Department, P/Bag 00704, Gaborone, Botswana.

E-mail: moidaki@mopipi.ub.bw

Key words: receiver functions, Midcontinent rift, Moho sharpness, crustal modification.

Acknowledgments: the teleseismic data used was obtained from Incorporated Research Institutions for Seismology (IRIS).

The diagrams in this paper were generated by Generic Mapping Tool (GMT version 4.2) a free software by Wessel and Smith (Free software helps map and display data. Eos Trans AGU 1991;72:441, 445-6). The authors also would like to thank Dr. S. Gao for his Fortran77 programs to make manuscript a success.

Received for publication: 10 March 2012.

Revision received: 24 January 2013.

Accepted for publication: 28 January 2013.

This work is licensed under a Creative Commons Attribution NonCommercial 3.0 License (CC BYNC 3.0).

@C Copyright M. Moidaki et al., 2013

Licensee PAGEPress, Italy

Research in Geophysics 2013; 3:e1

doi:10.4081/rg.2013.e1

teleseismic recordings from 25 broadband stations in the MCR rift (Figure 1). The two profiles used in this study traverses different terrains of different ages. The FA10-FA14 stations are located in the Mazatzal belt (1.61 to 1.68 Ga) and stations FA15 to FA17 are within the 1.1 Ga Keweenawan province. Stations FA18 to FA23 are situated in the 1.69 to $1.78 \mathrm{Ga}$ Northern Rhyolite terrain. ${ }^{12}$ The Moho within the MCR was imaged using converted $P$ to $S$ receiver functions of seismic data recorded by the Florida to Edmonton array (FLED array) by Wysession et al..$^{13}$ The data used in this study spans from 2001 to 2006 . The data used was acquired between epicentral angles of $30^{\circ}$ and $100^{\circ}$. The seismograms were band pass filtered between frequency range of $0.05 \mathrm{~Hz}$ and $1.5 \mathrm{~Hz}$ and were converted in to radial receiver functions by deconvolving the vertical component seismogram from the radial component seismogram. ${ }^{14}$ Visual inspection was carried out and those that show a clear $P$ wave arrival were used in receiver function analysis (Table 1). A total of 743 radial receiver functions from 25 stations were chosen. Receiver functions were then grouped into one degree bins according to their depth corrected epicentral distances and those in the same bins are then stacked in time domain. The positive PmS and PPmS and the negative PSmS phases can be observed clearly. 


\section{Materials and Methods}

Converted PmS phases originating from velocity discontinuities have been widely used for studying the crustal structure for several decades. ${ }^{15,16}$ Receiver functions are calculated by deconvolving the vertical component from the radial and tangential components and are used to isolate and identify $\mathrm{PmS}$ converted phases. ${ }^{2}$ A Gaussian low pass filter with a corner frequency of $0.5 \mathrm{~Hz}$ was applied to all receiver functions. For this study, we have used the $\mathrm{H}-\Phi$ stacking technique $(\mathrm{H}=$ Moho depth and $\Phi=V_{p} N_{s}=$ velocity ratio of $V_{p}$ and $V_{s}$ ) of Zhu and Kanamori. ${ }^{17}$ A series of candidate depths $\mathrm{Hi}$ in the range from 25 to $60 \mathrm{~km}$ in increments of $0.1 \mathrm{~km}$ and candidate $\mathrm{j}$ from 1.65 to 2.0 in increments of 0.0025 were used in the calculation of crustal thickness, $V_{p} / N_{s}$ ratios and Moho sharpness. For each $(\mathrm{Hi}, \Phi \mathrm{i})$ the moveout of PmS, PPms and PSmS was calculated using the formula of Dueker and Sheehan ${ }^{18}$ and Nair et al. ${ }^{19}$

The moveout for PmS, $t_{1}^{(i, j)}$ is given by

$$
t_{1}^{(i, j)}=\int_{-H i}^{0}\left[\sqrt{\left(\frac{V p(z)}{Q j}\right)^{-2}-p^{2}-} \sqrt{(V p(z))^{-2}-p^{2}}\right] d z(1)
$$

where $p$ is the $\mathrm{P}$ wave ray parameter, $\mathrm{Hi}$ is the depth of the candidate discontinuity, $ø j$ is the candidate $V_{p} / N_{s}$ and $V_{p}(z)$ is the P-wave velocity at depth z. the moveout time for PPmS, $t_{2}{ }^{(i, j)}$ is given by

$$
t_{2}^{(i, j)}=\int_{-H i}^{0}\left[\sqrt{\left(\frac{V p(z)}{Q j}\right)^{-2}-p^{2}}+\sqrt{(V p(z))^{-2}-p^{2}}\right] d z
$$

and that of PSmS, $t_{3}^{(i, j)}$ is given by

$$
t_{2}^{(i, j)}=\int_{-H i}^{0} 2\left[\sqrt{\left(\frac{V p(z)}{Q j}\right)^{-2}-p^{2}}\right] d z
$$

The receiver functions at each station were then stacked using

$$
A(H i, \phi j)=\sum_{k=1}^{n} w_{1} S_{k}\left(t_{1}^{(i, j)}\right)+w_{2} S_{k}\left(t_{2}^{(i, j)}\right)-w_{3} S_{k}\left(t_{3}^{(i, j)}\right)
$$

where $w_{l}, w_{2}$, and $w_{3}$ are weights, $\mathrm{S}_{\mathrm{k}}(\mathrm{t})$ are the receiver function amplitude values at the predicted arrival times $t_{1}, t_{2}$, and $t_{3}$ of the Ps, PpPs, and PsPs+PpSs phases for the $j$ th receiver function, and $\mathrm{n}$ is the number of receiver functions used. ${ }^{17}$ This method provides a robust estimate of crustal thickness and Poisson's ratio. Previous studies have shown that there is a strong trade-off between depth $(\mathrm{H})$ and velocity ratio $\left(V_{\mathrm{p}} N_{\mathrm{s}}\right)$. The ambiguity introduced by the trade off were reduced by incorporating the later arriving crustal reverberations $\mathrm{PpPs}$ and $\mathrm{PpSs}+\mathrm{PsPs}$ in a stacking procedure whereby the stacking itself transforms the time-domain receiver functions directly to objective function values in $\mathrm{H}-\Phi$ parameter space. ${ }^{14,17,20}$ The Moho depth was estimated by using the time difference between the $\mathrm{PS}_{\text {Moho }}$ phase and the first arrival. ${ }^{17}$ The expressions for calculating the time delays $\left(t_{\mathrm{PpPs}}\right.$ and $\left.t_{\mathrm{PpSs}+\mathrm{PsPs}}\right)$ for PsPs and PpSs+PsPs phases and $\mathrm{H}$ can be found in the paper by Nair et al..$^{19}$ The uncertainty in mean crustal velocity is incorporated into error estimates for $\mathrm{H}$ and $\Phi$ by specifying a normal distribution of $V_{p}$ values so that $95 \%$ of the values selected fall between 6.2 and $6.8 \mathrm{~km} / \mathrm{s}$, with a mean value of $6.5 \mathrm{~km} / \mathrm{s}$. The procedure of selecting $V_{p}$ and weights from the distribution described above and then performing the H- $\Phi$ stacking with bootstrapping was repeated 10 times. While performing the $H-\Phi$ stacking, the contribution of each of the receiver functions to the determination of $\mathrm{H}$ and was also weighted based on the least squares misfit value of the receiver functions. ${ }^{19}$

\section{Results}

\section{Crustal thickness from bootstrapping results}

Most of receiver functions show a well defined peak on the H- $\Phi$ plot and therefore both $\mathrm{H}$ and $\Phi$ can be determined with high confidence (Figure 2). Some stations show clear PmS but not PPmS or PSmS arrivals. Thus an optimal pair of $(H, \Phi)$ cannot be conclusively determined. For those stations an estimate of the crustal thickness was obtained by assuming an average $\Phi$ of 1.73 (stations st03, st04, and FA11). Most of the stations show well pronounced PmS phases whereas stations FA12 do not show three Moho phases and therefore neither $\mathrm{H}$ nor $\Phi$ can be determined. For these stations, the resulting maximum stacking amplitude (R) provides unrealistic Moho amplitudes values. For the entire study area, the resulting $\Phi$ values range from 1.775 to 1.90 , with a mean of 1.84 , and the crustal thickness ranges from 40 to $53 \mathrm{~km}$, with a mean of $41 \mathrm{~km}$. The $R$ values have a mean of 0.12 with a range of $0.05-0.32$ (Figure 3 ).

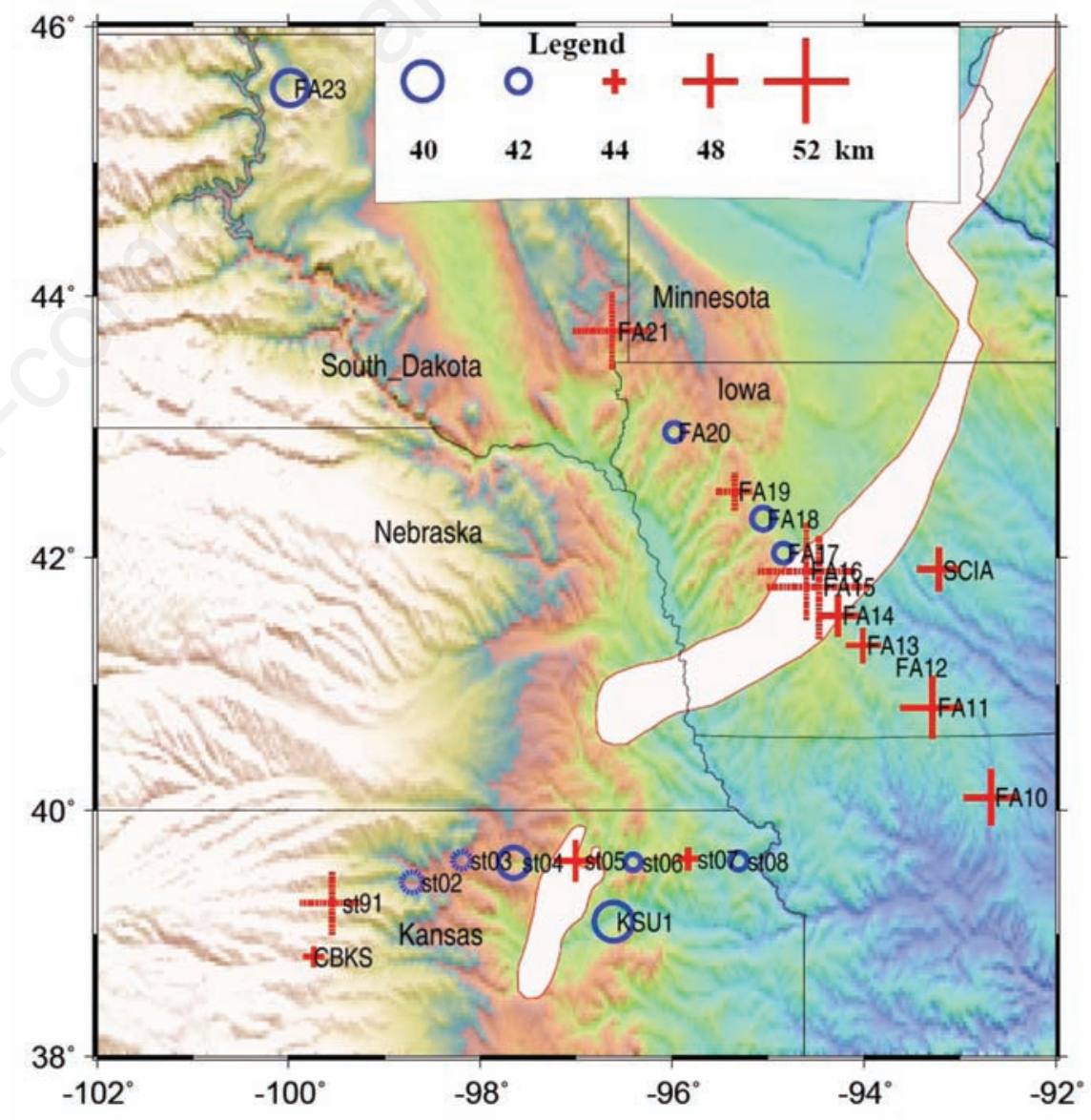

Figure 1. Topography map of the study area showing the Florida to Edmonton array and Kansas broadband teleseismic stations and the crustal thicknesses obtained from receiver function analysis. 


\section{Simple stack of receiver function}

The approach applied in this study makes use of a simple stack of receiver functions and the arrival times of the Ps and PpPs phases. An example of a simple receiver function stack is given in Figure 4. For most stations, the Ps and PpPs phases were easily picked on the receiver functions, but the PsPs+PpSs phase was not. However, for station st 05 , the PsPs+PpSs phase was more clearly identifiable than the PpPs phase, and in that case the later arriving phase was picked for the computation of $\mathrm{H}$ and Poisson's ratio. The receiver functions display a clear arrival in the time window of 3.5-6 s, which is considered as PmS, and at least one of the multiples near the vicinity of the predicted arrival times (calculated using $\Phi=1.73$ ). The phases at roughly $7 \mathrm{~s}$ on the stacks for st 05 seem too late for Moho conversions, and they may include interference between $\mathrm{PmS}$ and reverberations from discontinuities in the shallow crust which is shown by a strong PcS phase on stacked receiver function.

\section{Moho sharpness (R)}

Some of the PcS amplitudes are unusually large at some stations (e.g. FA11, FA14, FA22, st02, st04, st05 and st08, approaching or exceeding the direct $\mathrm{PmS}$ wave amplitude in some instances (Figure 4), which might be indicative of the presence of multiple, interfering arrivals. The amplitude ration ( $R$ ) for this stations ranges from 0.075 to 0.226 (Table 1) with st04 showing higher amplitude values $(\mathrm{R}=0.336)$. An alternative interpretation of high PcS amplitude could be due to the actual complexity in the Moho with lower $\mathrm{R}$ values representing a disturbed Moho. The Moho depth estimates obtained by averaging PmS-P times over all available back azimuths for all the stations are shown in Table 1. The overall pattern of a sharp north-west shallowing of the Moho beneath stations FA17 through FA23 is evident. The standard errors obtained for stations FA14 to FA18 are too large to provide an independent validation of velocity model details, but the precision is sufficient to confirm the presence magmatic underplating beneath FA14 through FA18 and st05. By stacking $\mathrm{PmS}$ receiver functions using a constant $\Phi$ of 1.73 for all the stations, it has been observed that the stacked amplitude of PmS in areas with thick crust is smaller than that in areas with thin crust. Another possible cause of the observed small stacking amplitudes is that the PmS phases originating from a deeper Moho are stacked less coherently. St05: The crustal thickness beneath the Proterozoic MCR in Kansas is among the thickest $(46.4 \mathrm{~km})$, with

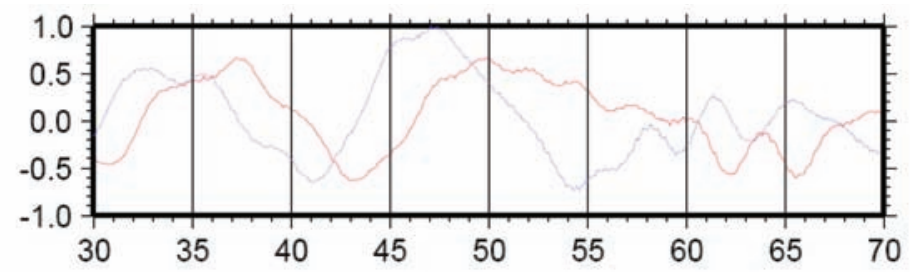

FA10; Dep $=47.1 ; \mathrm{Vp} / \mathrm{Vs}=1.827 ; n=9 ;$ Dep1.73= 49.9; stlat $=40.104 ;$ stlon $=-92.670$

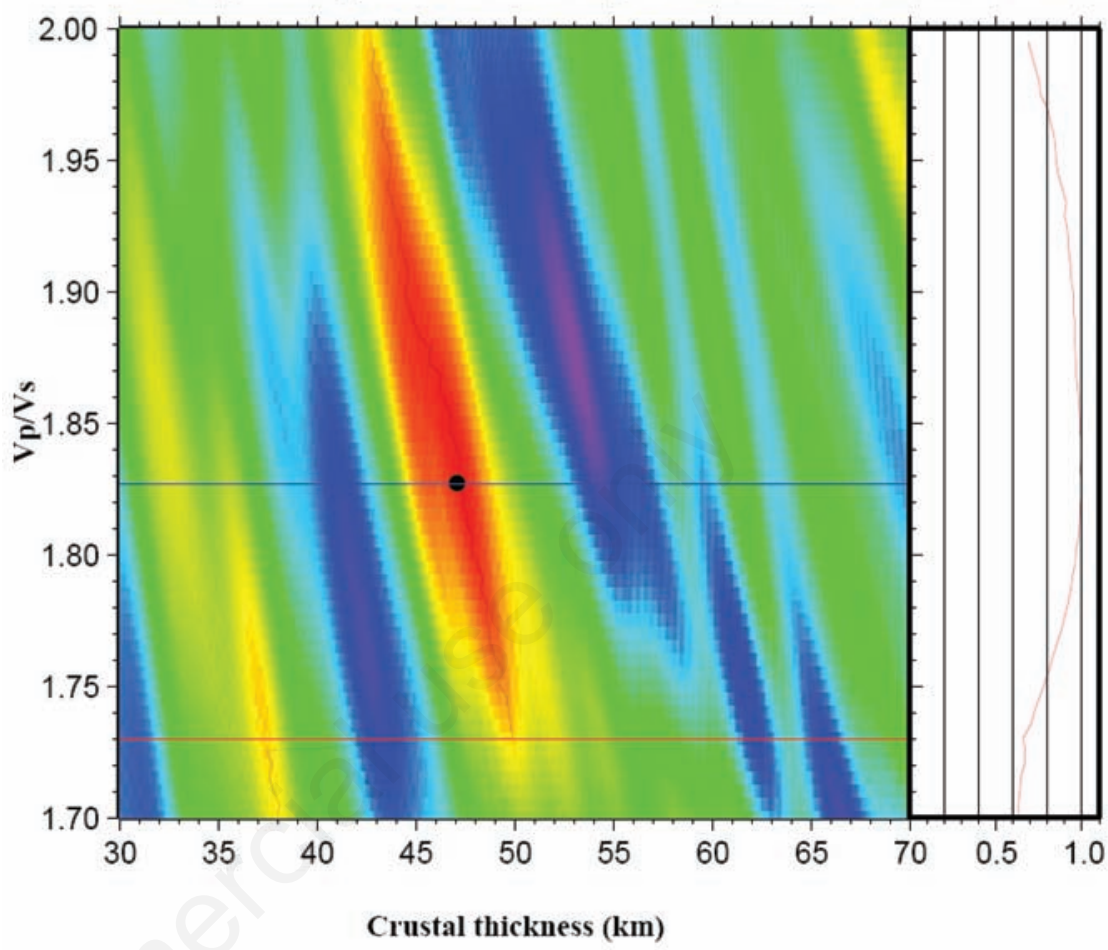

Figure 2. H- $\Phi$ stacking and bootstrap results for station FA10. The red line shows the stacking amplitudes for $\Phi=1.73$. The blue line was produced by using the optimal $\Phi$. The resulting crustal thickness, $\Phi$ and the crustal thickness when $\Phi=1.73$ is assumed (denoted as Dep1.73) are shown on the top panels.

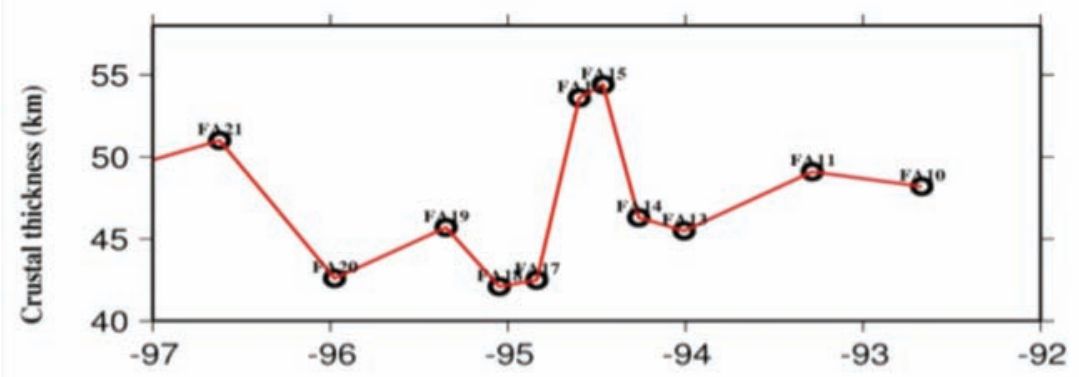

Figure 3. These transect show the variation of crustal thickness across the rift. Over-thickening $(\approx 53 \mathrm{~km})$ of crust is observed at stations within the rift (FA15 and FA16). 
significantly higher values of $\Phi$ (1.901) and low values of $R$ (0.072) measurements.

The MCR is characterized by over-thickened crust $(53.6 \mathrm{~km})$ using an average $\Phi$ of 1.73 . The PmS and PPmS phases are weakly detected for this station. The $\mathrm{R}$ values observed within the rift are lower than those observed on the rift flanks, and the crustal thickness shows a somewhat decreasing trend (FA10 to FA13) and then the thickness increases from station FA14 to FA17 and decrease to FA18 and then increase from FA18 to FA23. Crustal thickening depicted by stations FA13 through FA17 correspond to high $\Phi$ values (observed at FA17 with multiples) and hence lower $R$ values. Permanent broadband stations CBKS, PKS (same location as st91) and SCIA (same location as FA21) were also considered in this study (Figure 1). These stations show strong PmS phases with PKS showing a strong PcS phase. The averaged $\mathrm{H}, \mathrm{V}_{\mathrm{p}} \mathrm{N}_{\mathrm{s}}$ and $\mathrm{R}$ values are shown in Table 1. The large contrast in crustal thickness and sharpness between the CBKS and st05 stations suggests that the crust has different characteristics (Figure 5).

\section{Discussion}

Studies by Donaldson and Irving, ${ }^{21}$ Burke and Dewey ${ }^{22}$ state that the MCR rift transects the Grenville Front, a complex geologic boundary of approximately the same age as the rift but variously interpreted as a suture zone resulting from plate collision. However, the junction or contact between these two major structures is hidden beneath thick Paleozoic sediments and the nature of this contact is obscure. ${ }^{23}$ It is reasonable to conclude that the high and $\mathrm{H}$ values observed in the vicinity of the MCR are due to basalt intruding the crust from the mantle below. The compressional forces from the Grenville orogeny is believed have stopped the rift in Proterozoic North America to the east of the Midcontinent region, the combination of high-grade metamorphism, reworked continental crust, compressional structures, and abundant crustal material strongly suggests that the Grenville Province represents a continental collision. ${ }^{5}$ According to Baer, ${ }^{24}$ much of the igneous and metamorphic activity of the Grenville event occurred 1150-900 Myr ago, with an earlier peak of activity $1100 \pm 50 \mathrm{Myr}$ ago and a second peak of activity $950 \pm 50 \mathrm{Myr}$ ago. The proximity in time and space of the Grenville Province and the midcontinent rift system has led to suggestions that the two are genetically related. Because of large volumes of basaltic magma associated with the Midcontinent rift system, an active-type system seems more probable. However, because of the proximity of the Grenville Province, it is possible that extensional forces behind a continental collisional zone may have contributed significantly to the development of the rift. ${ }^{5,23,25,26}$ In the context of an active model for the formation of the Midcontinent rift system, several authors have proposed that the Lake Superior basin is situated over a former hotspot, that a rifting (rrr) triple junction formed, but that only two of the arms (the MCR and mid-Michigan segments) developed extensively.

Models of passive origin have been proposed by Donaldson and Irving. ${ }^{21}$ These are generally related to the stress field established in the

Table 1. Observations of crustal thickness $\left(H, H_{n}\right)$, Poisson's ratio $\left[V_{p} / V_{s}(\Phi)\right]$ and the sharpness of the Moho $(R)$.

\begin{tabular}{|c|c|c|c|c|c|c|c|c|c|c|c|c|}
\hline Station & Long, deg & Lat, deg & H, km & $\Phi$ & $\mathrm{H}_{\mathrm{n}}, \mathrm{km}$ & $\Delta \mathbf{H}$ & $\Delta \Phi$ & $\Delta \mathbf{H}_{n}$ & $\mathbf{R}$ & $\Delta \mathbf{R}$ & $\mathrm{N}^{\mathrm{rfs}}$ & Q \\
\hline CBKS & -99.737 & 38.814 & 43.7 & 1.819 & 49.0 & 0.15 & 0.003 & 0.08 & 0.133 & 0.005 & 209 & A \\
\hline ECSD & -96.600 & 43.730 & 43.8 & 1.854 & 49.8 & 1.87 & 0.030 & 1.55 & 0.228 & 0.004 & 2 & A \\
\hline FA10 & -92.670 & 40.104 & 48.2 & 1.787 & 49.5 & 0.54 & 0.020 & 0.22 & 0.119 & 0.034 & 9 & A \\
\hline FAll & -93.287 & 40.819 & 36.1 & 1.985 & 49.1 & 1.41 & 0.032 & 0.28 & 0.105 & 0.016 & 23 & B \\
\hline FA12 & -93.711 & 41.139 & 40.1 & 1.849 & 44.8 & 0.12 & 0.008 & 0.00 & 0.142 & 0.027 & 13 & C \\
\hline FAl3 & -94.008 & 41.313 & 45.5 & 1.781 & 46.7 & 0.22 & 0.004 & 0.18 & 0.182 & 0.012 & 24 & A \\
\hline FA14 & -94.264 & 41.545 & 46.3 & 1.775 & 47.5 & 0.22 & 0.002 & 0.22 & 0.226 & 0.013 & 19 & A \\
\hline FA15 & -94.465 & 41.772 & 44.3 & 1.888 & 54.4 & 2.89 & 0.084 & 2.14 & 0.100 & 0.002 & 41 & B \\
\hline FA16 & -94.598 & 41.893 & 53.4 & 1.738 & 53.6 & 0.43 & 0.016 & 0.00 & 0.134 & 0.013 & 27 & B \\
\hline FAl7 & -94.838 & 42.035 & 42.5 & 1.902 & 48.6 & 0.16 & 0.007 & 9.78 & 0.138 & 0.011 & 47 & A \\
\hline FA18 & -95.049 & 42.302 & 42.1 & 1.809 & 45.8 & 0.28 & 0.009 & 2.39 & 0.214 & 0.007 & 27 & A \\
\hline FA19 & -95.349 & 42.512 & 42.4 & 1.816 & 45.7 & 1.15 & 0.020 & 0.70 & 0.135 & 0.008 & 29 & B \\
\hline FA20 & -95.977 & 42.970 & 42.6 & 1.866 & 50.0 & 0.24 & 0.007 & 0.87 & 0.197 & 0.019 & 31 & A \\
\hline FA21 & -96.624 & 43.738 & 47.2 & 1.803 & 51.0 & 0.55 & 0.010 & 0.58 & 0.111 & 0.012 & 37 & B \\
\hline FA23 & -99.984 & 45.550 & 40.5 & 1.829 & 44.9 & 0.14 & 0.004 & 3.32 & 0.295 & 0.014 & 17 & A \\
\hline KSU1 & -96.609 & 39.101 & 48.3 & 1.707 & 47.7 & 0.00 & 0.004 & 0.07 & 0.124 & 0.025 & 70 & A \\
\hline PKS & -99.541 & 39.257 & 40.5 & 1.848 & 44.8 & 4.31 & 0.064 & 0.35 & 0.192 & 0.014 & 14 & A \\
\hline SCIA & -93.215 & 41.907 & 46.6 & 1.785 & 49.5 & 0.33 & 0.015 & 1.75 & 0.249 & 0.017 & 12 & A \\
\hline st02 & -98.710 & 39.421 & 41.7 & 1.758 & 42.3 & 1.13 & 0.032 & 0.28 & 0.175 & 0.015 & 6 & B \\
\hline st03 & -98.193 & 39.599 & 33.8 & 1.955 & 42.7 & 0.43 & 0.005 & 1.19 & 0.387 & 0.101 & 2 & B \\
\hline st04 & -97.652 & 39.578 & 33.6 & 1.956 & 53.9 & 0.90 & 0.006 & 8.78 & 0.334 & 0.061 & 2 & A \\
\hline st 05 & -97.006 & 39.597 & 46.4 & 1.901 & 56.1 & 0.00 & 0.011 & 0.85 & 0.072 & 0.002 & 31 & A \\
\hline st06 & -96.406 & 39.582 & 42.9 & 1.776 & 44.0 & 0.25 & 0.009 & 0.42 & 0.097 & 0.017 & 8 & A \\
\hline st07 & -95.827 & 39.608 & 43.8 & 1.800 & 46.7 & 1.13 & 0.023 & 1.18 & 0.212 & 0.029 & 5 & A \\
\hline st08 & -95.305 & 39.592 & 42.7 & 1.778 & 44.8 & 1.32 & 0.029 & 0.32 & 0.198 & 0.011 & 14 & A \\
\hline st91 & -99.549 & 39.254 & 36.2 & 1.980 & 49.3 & 0.15 & 0.014 & 0.47 & 0.168 & 0.018 & 16 & B \\
\hline
\end{tabular}

Long, longitude; deg, degree; Lat, latitude; $\mathrm{H}$, crustal thickness. R is the ratio amplitude of the Direct P and its converted phase; Nris is the number of receiver function used for calculating $\mathrm{H}$ and Poisson's ratio $\left(\mathrm{V}_{\mathrm{p}} \mathrm{N}_{\mathrm{s}}\right)$; Q is the category of quality of H- $\Phi$ plots. 
North American plate in conjunction with the development of the Grenville Province. One of the factors complicating attempts to fit models of this type into development of the MCR is that a detailed understanding of the Grenville Province is still far from complete. ${ }^{24}$ The MCR is a very large crustal feature, comparable in scale with the current East African rift system. There appears to be little doubt that the observed $V_{p} / V_{s}$ ratios, low values of $R$ are a result of active rifting which is a major component in development Midcontinent Rift, rather than passive, forces. Stewart ${ }^{27}$ and Sawkins ${ }^{28}$ have pointed out that the development of the MCR occurred at a time during which rifting was prevalent throughout the world, and thus it may be related to a major extensional stress field that developed at this time in continental lithosphere, perhaps as a result of widespread plate movement and breakup.

Thiel ${ }^{29}$ showed that the central positive gravity anomaly is associated with Keweenawan basalt deposited in an elongate depression, and that the flanking minima correlate with prisms of clastic rocks that thin away from the central gravity high. The central basin of basalt has been disrupted along high-angle reverse faults and brought into juxtaposition with younger sedimentary rocks. The latter were deposited in later, broader basins that originally completely covered the basalts, and the faults generally parallel the axis of the central, basalt-filled basin. The Moho depths appear to be variable across the profiles. Between FA09 and FA13, the Moho appears to be at a relatively constant depth. From FA14 through FA17, the Moho depths increase towards the center of the Midcontinent Rift, indicating that the Moho is deepening and agreeing with previous studies by Hinze et al. ${ }^{7,30}$ showing crustal thickening beneath the rift.

The thickest crust of about $53 \mathrm{~km}$ is observed at the center of the rift and is similar to results from some of the previous studies by Steinhart and Smith, ${ }^{10}$ Halls, ${ }^{11}$ Campbell and Griffiths. ${ }^{31}$ The thickening, together with the elevated $\mathrm{Vp} / \mathrm{Vs}$ and decreased crustal sharpness along the rift, suggests the existence of an underplated mafic layer beneath the original Moho. According to Campbell and Griffiths, ${ }^{31}$ Cannon and Hinze, ${ }^{32}$ the decrease in tensile stress imparted by Grenvillian tectonism resulted in ponding of the magma at the crust mantle boundary and hence an overthickening of the crust in Midcontinent Rift. The generation of felsic melts and the ductile lower crust would have created density and rheologic barriers to impede the passage of mafic melts and promote magmatic ponding. ${ }^{33}$ Once ponding of magma has initiated, mafic magma chambers would have continued to grow as additional rising mantle melts became trapped and triggered more widespread melting of the lower crust. After extending beyond the northwestern portion of the rift in Iowa, the crust appears to become thinner, then thicken around Williston Basin, and again become thinner in Alberta. Our study shows that the values of $\Phi$ are high along both profiles indicative of magmatic underplating-volcanic intrusions beneath the rift and represent the subsequent addition of a mafic component, rather than variability that was present since the formation of the crust. The low values of $\Phi$ elsewhere and their apparent age independence place important constraints on models for crustal formation and evolution.

Gravity studies played a critical role in the early delineation of the MCR. ${ }^{29,34}$ These methods readily detect the associated large physical property contrasts. ${ }^{7,35}$ Intense gravity anomalies are observed over the length of the rift as positive gravity anomalies where the volcanic
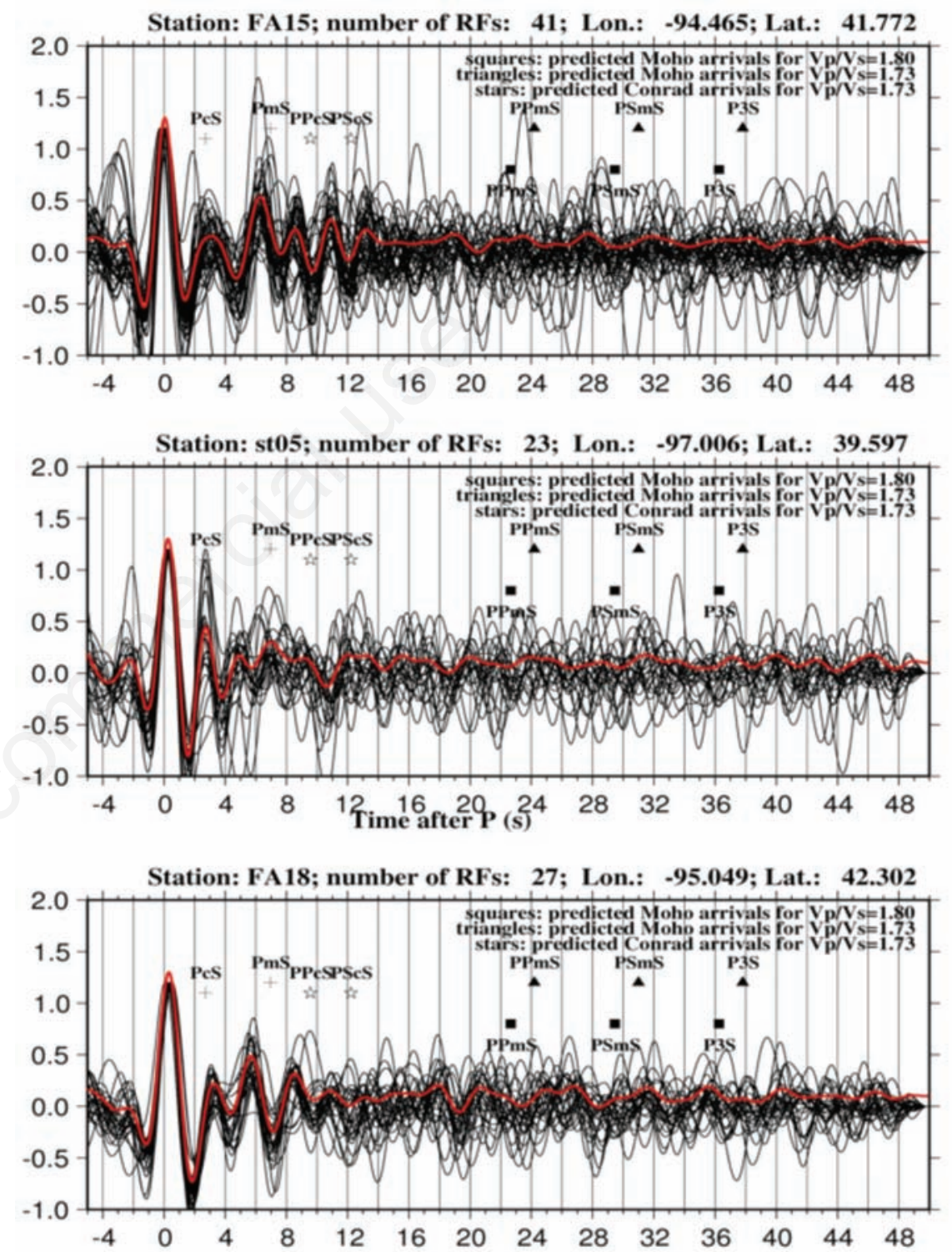

Figure 4. Example receiver functions st05, FA15 and FA18. The red trace from each station is the result of simple time domain summation (without move-out correction) of the individual traces. Triangles are theoretical arrival times for PPmS and PSmS calculated using equations (2) and (3) of Nair et al. ${ }^{19}$ by taking $P=5.0 \mathrm{~s} / \mathrm{deg}, V_{p}=6.5 \mathrm{~km} / \mathrm{s}$, and $\Phi=1.73$. the plot shows a strong PcS phase suggesting a subcrustal interface. The time difference between the PmS and the direct arrival is approximately $5 s(\sim 40 \mathrm{~km}$ of crustal thickness). The amplitude ratio $(R)$ beneath this station is $\approx 0.1$ suggesting a weakened or disturbed Moho. 
rocks are prominent and negative and featureless anomalies over sedimentary basins. The general anomaly rises to over $60 \mathrm{mGal}$ in Minnesota with adjacent marginal minima that are less than $80 \mathrm{mGal}$ below the regional level in Iowa. Gravity anomaly of the rift is the most striking feature in the gravity anomaly map of the central Midcontinent and is the principal method for delineating the extent of the rift. Gravity modeling results show mafic intrusive in the sub-rift continental crust and thickening of the crust. Our gravity modeling results (not presented in this paper) are consistent with the results from Hinze et al. ${ }^{7}$ The crustal thickness determined from receiver function studies along FLED and Kansas array show an over-thickening of the crust along the rift. Over-thickening of the crust has been observed across the western Lake Superior from gravity 2-D models constrained with seismic data.?

The amplitude of the converted phase can be affected by lateral variation in Moho depths. ${ }^{19}$ The observed crustal thickness (Figure 1) suggests that the Moho in the study area is fairly discontinuous or disturbed, and thus variation in Moho depth is likely to affect the amplitude of the converted phases. Velocity heterogeneities in the crust beneath the area surrounding a station can also affect the $\mathrm{PmS}$ amplitudes. The crustal volume traversed by the rays can results to incoherent stacking ${ }^{19}$ and consequently reduction in the stacked amplitude of the converted phases. The influence of the topography of velocity interfaces in the crust ${ }^{19}$ could also affect the amplitude of the converted phases.

Stations located west of the MCR record uniformly weak Moho amplitude. This small amount of converted energy may result from a reduced shear wave speed and/or density contrast across the crust - mantle interface. The Moho amplitude (PmS) on the eastern side of the rift (stations FA10 to FA14) is considerably

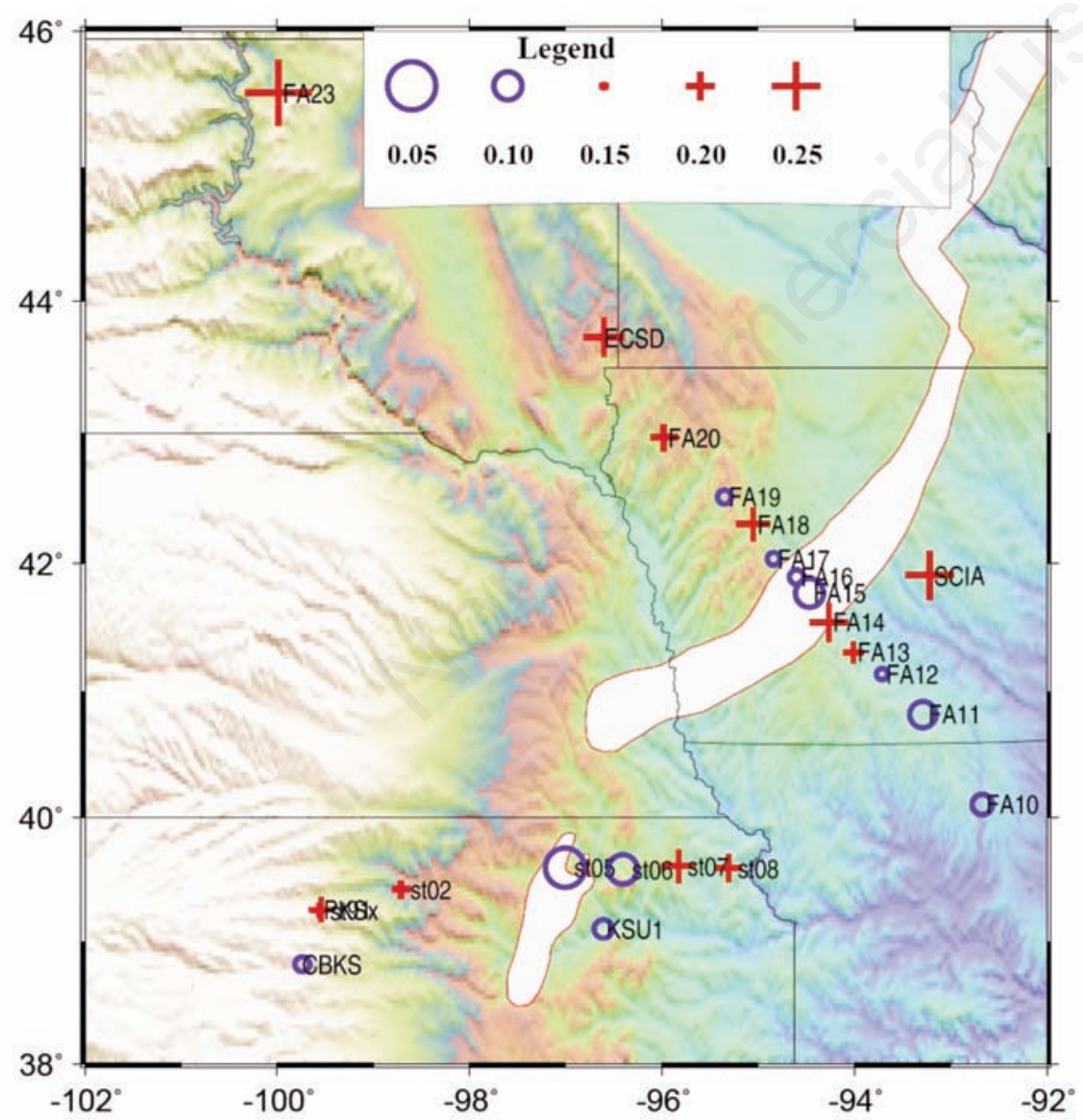

Figure 5. Amplitude ratio ( $R$ ) calculated from stacking amplitude corresponding to the optimal pair of $(H, \Phi)$ over that of direct $P$ wave and the radial component. The amplitude ratio shows varying Moho signatures across the Midcontinent rift. The quality of the Moho (based on the calculated $R$ values) varies from station to station without a clear pattern but low $R$ values are observed in stations st05, st02, FA11 to FA12, FA16 and FA17. The Moho seems to be segmented probably as a result of extension that occurred million years ago. greater suggesting a more rapid transition from crust to mantle or a larger impedance contrast at the base of the crust; either slow or low density crust atop normal mantle or alternatively normal lower crust atop fast or high density mantle.

\section{Conclusions}

We have found the Moho depth along this array to vary between $40 \mathrm{~km}$ and $53.6 \mathrm{~km}$, assuming a constant $\mathrm{V}_{\mathrm{p}}$ of $6.6 \mathrm{~km} / \mathrm{s}$ and a $\mathrm{V}_{\mathrm{p}} / \mathrm{N}_{\mathrm{s}}$ ratio of 1.82 for the entire array. The Moho is at its shallowest at either end of the array and thickens significantly beneath the Appalachians (station FA10), the Midcontinent Rift (station FA14, FA15, FA16, FA17), and Williston Basin (FA23). The Poisson's ratio values vary from 0.26 to 0.305 in the vicinity of the rift probably as a result of varying sediment deposition and erosion processes after cessation of rifting. Lower values of $\mathrm{H}, \mathrm{R}$ and higher values of $\Phi$ indicate that the crust was subjected to extensional forces which thinned the crust. Lower values of $\mathrm{R}$ within the rift further suggest the Moho is disturbed as result of dike intrusion or magmatic underplating whereas on the rift flanks the amplitude ratio (R) is well pronounced suggesting less disturbed Moho. The MCR in Kansas State shows slightly lower $\mathrm{H}(\sim 46 \mathrm{~km}), \mathrm{R}(0.1$ to 0.15$)$ and elevated $\Phi$ $(\sim 1.80)$ values. On either side of the rift the crustal thickness ranges from 42 to $49 \mathrm{~km}$ and Poisson's ratios vary from 0.24 to 0.28 . The results indicate that the crust beneath the MCR has been modified by rifting and magmatism.

\section{References}

1. Gao SS, Liu KH, Chen C. Significant crustal thinning beneath the Baikal rift zone: new constraints from receiver function analysis. Geophys Res Lett 2004;31: L20610.

2. Al-Damegh K, Sanvol E, Barazangi M. Crustal structure of the Arabian plate: new constraints from the analysis of teleseismic receiver functions. Earth Planet Sci Lett 2005;231:177-96.

3. Dugda MT, Nyblade AA, Julia J, et al. Crustal structure on Ethiopia and Kenya from receiver function analysis: implications for rift development in eastern Africa. J Geophys Res 2005;11:B01303.

4. Cannon WF, Daniels DL, Nicholson SW, et al. New map reveals origin and geology of North American Mid-continent Rift. EOS 2001;82:97-101.

5. Van Schmus WR, Hinze WJ. Midcontinent Rift system. In: Hatcher RD Jr, Thomas 
WA, Viele GW, eds. The geology of North America, vol. C-2, Precambrian: Conterminous United States. Boulder, CO: Geological Society of America; 1989. pp 292-303.

6. Nyquist JE, Wang HF. Flexural modeling of the Midcontinent Rift. J Geophys Res 1988;93:8852-68.

7. Hinze WJ, Wold RJ, G'Hara NW. Gravity and magnetic anomaly studies of Lake Superior. Geol Sot Am Mem 1982;156:203222.

8. Behrendt JC, Green AG, Cannon WF, et al. Crustal structure of the Midcontinent rift system: Results from GLIMPCE deep seismic reflection profiles. Geology 1988; 16 : 81-5.

9. Behrendt JC, Hutchinson DR, Lee MW, et al. GLIMPCE seismic reflection evidence of deep-crustal and upper-mantle intrusions and magmatic underplating associated with the Midcontinent Rift system of North America. Tectonophysics 1990;173: 595-615.

10. Steinhart JS, Smith TJ. The Earth Beneath the Continents. Am Geophys Union Geophys Monogr 1966;10:663.

11. Halls HC. Crustal thickness in the Lake Superior region. In: Wold RJ, Hinze WJ, eds. Geology and tectonics of the Lake Superior basin. Boulder, C0: The Geological Society of America, Memoir 156;1982. pp 239-43.

12. Carmichael RS, Black RA. Analysis and use of MAGSAT satellite magnetic data for interpretation of crustal structure and character in the U.S. mid-continent. Phys Earth Planet Int 1986;44:333-47.

13. Wysession ME, Fischer KM, Shore PJ, Aleqabi GI. Waves across America: using a seismic array from Florida to Alberta to examine the geology beneath the middle of North America. Abstracts of the 38th Annual Meeting of the North-Central Section of the Geological Society of America, St. Louis, M0, 2004.

14. Ammon CJ, Randall GE, Zandt G. On the non-uniqueness of receiver function inversions. Geophys Res 1990;95:15303-
18.

15. Langston CA. Structure under Mount Ranier, Washington, inferred from teleseismic body waves. J Geophys Res 1979; 84:4749-62.

16. Owens TJ, Zandt G, Taylor SR. Seismic evidence for an ancient rift beneath the Cumberland Plateau, Tennessee: a detailed analysis of broadband teleseismic P waveforms. J Geophys Res 1984;89:778395.

17. Zhu LP, Kanamori H. Moho depth variation in southern California from teleseismic receiver functions. J Geophys Res 2000; 105:2969-80.

18. Dueker KG, Sheehan AF. Mantle discontinuity structure beneath Colorado Rocky Mountains and High Plains. J Geophys Res 19993;103:7153-69.

19. Nair KS, Gao SS, Liu KH, Silver PG. Southern African crustal evolution and composition from receiver function studies. J Geophys Res 2006;111:B02304.

20. Zandt G, Myers SC, Wallace TC. Crust and mantle structure across the Basin and Range - Colorado plateau boundary at $370 \mathrm{~N}$ latitude and implications for Cenozoic extensional mechanism. J Geophys Res 1995;100:10529-48.

21. Donaldson JA, Irving E. Grenville Front and rifting of the Canadian Shield. Nature Phys Sci 1972;237:139-40.

22. Burke K, Dewey JF. Plume-generated triple junctions: key indicators in applying plate tectonics to old rocks. J Geol 1973;81:40633 .

23. Green JC. Geochemical evidence for the nature and development of the middle proterozoic (Keweenanwan) mid-continent rift of North America. Tectonophysics 1982;94:313-437.

24. Baer AJ. A Grenvillian model of Proterozoic plate tectonics. In: Precambrian plate tectonics. Amsterdam: Elsevier; 1981. pp 353385.

25. Van Schmus WR, Green JC, Halls HC. Geochronology of Keweenawan rocks in the Lake Superior region. In: Wold RJ, Hinze WJ, eds. Geology and tectonics of the Lake Superior basin. Boulder, C0: The Geological Society of America, Memoir 156; 1982. pp 165-72.

26. Van Schmus WR, Hinze WJ. The Midcontinent Rift System. Ann Rev Earth Planet Sci 1985;13:345-83.

27. Stewart JH. Late Precambrian evolution of North America: plate tectonics implication. Geology 1976;4:11-5.

28. Sawkins FJ. Widespread continental rifting: some considerations of timing and mechanism. Geology 1976;4:427-30.

29. Thiel EC. Correlation of gravity anomalies with the Keweenawan geology of Wisconsin and Minnesota. Geol Soc Am Bull 1956;67:1079-100.

30. Hinze WJ, Braile LW, Chandler VW. A geophysical profile of the southern margin of the Midcontinent Rift System in western Lake Superior. Tectonics 1990;9:303-10.

31. Campbell IH, Griffiths RW. Implications of mantle plume structure for the evolution of flood basalts. Earth Planet Sci Lett 1990; 99:79-93.

32. Cannon WF, Hinze JW. Speculations on the origin of the North American Midcontinent rift. Tectonophysics 1992; 213:49-55.

33. Huppert HE, Sparks RSJ. The generation of granitic magmas by intrusion of basalt into continental crust. J Petrol 1988;29: 599-624.

34. Hinze WJ. Regional gravity and magnetic anomaly maps of the Southern Peninsula of Michigan. Michigan Geol Surv Rep Invest 1963;1:26.

35. Klasner JS, Cannon WF, Van Schmus WR. The pre-Keweenawan tectonic history of the north-central United States and central Canada and its influence on formation of the Midcontinent Rift. In: Wold RJ, Hinze WJ, eds. Geology and tectonics of the Lake Superior basin. Boulder, C0: The Geological Society of America, Memoir 156; 1982. pp 27-46. 